This document is the Accepted Manuscript version of a Published Work that appeared in final form in ChemSoc.Rev, copyright (C) The Royal Society of Chemistry 2017 after peer review and technical editing by the publisher. To access the final edited and published work see: https://pubs.rsc.org/en/content/articlelanding/2017/gc/c7gc02692g\#! divAbstract

\title{
A mechanism for the selective epimerization of the glucose mannose pair by Mo-based compounds: towards catalyst optimization $\uparrow$
}

\begin{abstract}
M. Rellán-Piñeiro, (iD ${ }^{a}$ M. Garcia-Ratés (D) $^{b}$ and N. López (D) *a
The selective $C^{2}$ epimerization of the glucose/mannose pair on a set of Mo-based catalysts was studied by means of density functional theory. The process, known as the Bilik reaction, encompasses a 1,2 $\mathrm{C}$-shift of the $\mathrm{C}^{3}$ centers at the sugars. Molybdic acid was initially proposed as a catalyst in this reaction, and recent experimental studies have shown that the polyoxometalate (POM) Keggin cluster $\mathrm{H}_{3} \mathrm{PMO}_{12} \mathrm{O}_{40}$ also presents a good performance. In the present work, we propose a reaction mechanism for the epimerization on the Keggin cluster with different heteroatoms and extend it to a larger $\mathrm{POM}, \mathrm{H}_{6} \mathrm{P}_{2} \mathrm{MO}_{18} \mathrm{O}_{62}$, and the continuous $\alpha-\mathrm{MoO}_{3}(010)$ surface. We have found that in the transition state corresponding to the 1,2 C-shift the Mo center acts as an electron buffer that promotes the transformation of the aldehyde group in $C^{1}$ into an alkoxy group and the $C^{2}$ alkoxy into an aldehyde group. As a consequence, the activity of Mo-containing compounds can be traced back to the reducibility of the Mo center and a simple microkinetic model illustrates that this descriptor generates an activity volcano. This allows the identification of a new POM that shall be 4.7 times more active than the parent compound. We have thus shown that continuum models linking the properties of molecular cluster-like catalysts and oxide surfaces can be derived and this paves the way towards a unified theory in catalysis.
\end{abstract}

\section{Introduction}

Obtaining compounds with controlled chirality is a challenge to develop platform chemicals from biomass. Some of the target compounds could be easily generated from sugars but in some cases the natural abundance of the parent sugar is relatively small (rare sugars) whereas their epimers are widely abundant. The chemical toolbox now allows epimerization reactions, ${ }^{1}$ that is, the rearrangement of a single stereogenic center in a molecule that contains several of them. ${ }^{2}$ In nature, epimerases catalyze this reaction at multiple carbon positions providing a high specificity for products, ${ }^{3,4}$ but their transfer to the industrial scale suffers from the very specific conditions of temperatures and $\mathrm{pH}$ as well as difficult recycling. ${ }^{5}$ Therefore, there is a need to develop inorganic catalysts that can allow the successful epimerization avoiding these drawbacks.

Lobry de Bruyn-Alberda van Ekenstein observed that during the isomerization of aldoses to ketoses promoted by a

${ }^{a}$ Institute of Chemical Research of Catalonia, ICIQ, and The Barcelona Institute of Science and Technology, Av. Països Catalans 16, 43007 Tarragona, Spain. E-mail: nlopez@iciq.es

${ }^{b}$ Max Planck Institute for Chemical Energy Conversion, Stiftstrasse 34-36, D-45470 Mülheim an der Ruhr, Germany

$\dagger$ Electronic supplementary information (ESI) available. See DOI: 10.1039/ c7gc02692g base, epimers were obtained as byproducts. ${ }^{6}$ Lewis acids like $\mathrm{Ni}^{+2}$ diamines in methanol are active and the equilibrium is reached only in $5 \mathrm{~min}$ at $60{ }^{\circ} \mathrm{C}^{7,8}$ However, the catalyst is complex and the reactivity is limited by the low solubility of sugars in methanol. ${ }^{9}$ Other Lewis acids like metal(III) chlorides $\left(\mathrm{CrCl}_{3}, \mathrm{AlCl}_{3}, \quad \mathrm{InCl}_{3}, \mathrm{LaCl}_{3}, \mathrm{DyCl}_{3}\right.$, and $\left.\mathrm{YbCl}_{3}\right)$ epimerize glucose to fructose, giving mannose as a secondary product. ${ }^{10}$ Alternatively, the Sn-Beta zeolite has also been proposed as an active catalyst for epimerization; framework Sn sites are active in methanol, ${ }^{11}$ and partially hydrolyzed Sn sites catalyze the reaction when $\mathrm{Na}^{+}$is added to the reaction media. ${ }^{12}$ Borate salts also activate the Sn-Beta zeolite for epimerization reactions. ${ }^{13,14}$ Mechanistic investigations by ${ }^{13} \mathrm{C}$ and ${ }^{1} \mathrm{H}$ NMR showed that epimerization proceeds via 1,2 C-shift and, in some cases, also by $\mathrm{C}^{1}-\mathrm{C}^{2}$ hydride transfer. Generally, these catalysts perform the reaction via the coordination of the sugar to only one metal center.

However, the most prominent inorganic catalysts are based on Mo. Mo-Catalysts have found several applications in biomass conversion and, most recently, also when employed as single atoms or small clusters. ${ }^{15-21}$ In the 1970 s, Bilik and coworkers $^{22}$ reported the epimerization of aldoses at the $\mathrm{C}^{2}$ position catalyzed by molybdates under acidic conditions and gave name to the reaction. ${ }^{23}$ In their experiments, the thermodynamic equilibrium between the aldose pair was reached after $3 \mathrm{~h}$ at $90{ }^{\circ} \mathrm{C}$, and the reaction was quite neat. In 1982 , 

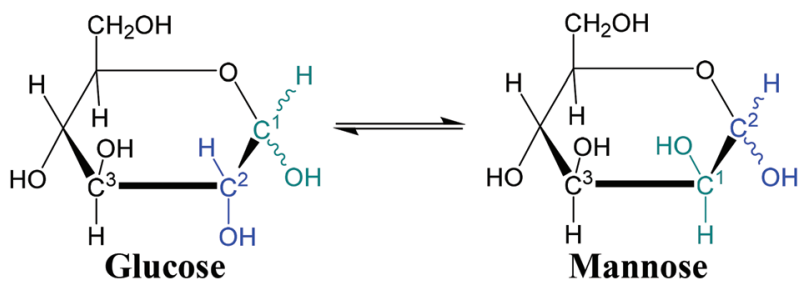

Scheme 1 Schematic representation of the epimerization of glucose to mannose. The carbons where the rearrangement occurs are marked in colors illustrating the chiral nature of the $C^{2}$ positions.

NMR-based mechanistic studies ${ }^{24}$ with labeled ${ }^{13} \mathrm{C}^{1}$ and ${ }^{13} \mathrm{C}^{2}$ aldoses showed a stereospecific carbon-skeleton rearrangement during the reaction formally leading to the $\mathrm{C}^{2}$ epimerization by $\mathrm{C}^{1}-\mathrm{C}^{2}$ carbon shift (Scheme 1).

The mechanistic studies with molybdates ${ }^{24-26}$ indicate that the reaction is intramolecular and takes place through the open form of the aldose. The accepted molecular mechanism presented in Scheme 2 requires two Mo-centers to occur. The hydrated aldose coordinates through the four hydroxyl groups $\mathrm{C}^{1}-\mathrm{C}^{4}$ (the oxygen atoms on $\mathrm{C}^{1}$ and $\mathrm{C}^{4}$ are attached to Mo atoms, while the oxygen atoms on $\mathrm{C}^{2}$ and $\mathrm{C}^{3}$ form a bridge between Mo). ${ }^{23,27}$ Then, in the transition state, the $\mathrm{C}^{3}-\mathrm{C}^{2}$ breaks while $\mathrm{C}^{3}-\mathrm{C}^{1}$ is simultaneously formed. This process is accompanied by the dehydration of $\mathrm{C}^{1}$ and hydration of $\mathrm{C}^{2}$. The chain rearrangement leads to the inversion of configuration in $\mathrm{C}^{2}$ obtaining the epialdose-dimolybdate complex. The presence of a terminal aldehyde group and hydroxyl groups in $\mathrm{C}^{2}$ and $\mathrm{C}^{3}$ is essential, and the alcohol group is not needed in position $\mathrm{C}^{4}$, although it enhances the rate. Using Density Functional Theory, DFT, only the epimerization step has been studied with Mo oxide dimers and tetramers and due to rigidity, the former was found to be better for this elementary step. $^{28}$

Molecular oxides, like the molybdenum-based polyoxometalate (POM) $\mathrm{H}_{3} \mathrm{PMo}_{12} \mathrm{O}_{40}$, are also active and highly selective catalysts, more than $90 \%$, in aqueous solution and acid media $(\mathrm{pH}=2.5-3.5) .{ }^{19}$ By ${ }^{13} \mathrm{C}$ NMR the $\mathrm{C}^{1}-\mathrm{C}^{2}$ carbon shift reported in the Bilik reaction was found and XPS identified electron transfer from glucose to the Mo octahedra units. The kinetic studies reported apparent activation barriers between 95 and $100 \mathrm{~kJ} \mathrm{~mol}{ }^{-1}$, thus slightly lower than those reported for molybdic acid, $126 \mathrm{~kJ} \mathrm{~mol}^{-1} \cdot{ }^{29}$ More importantly, the catalyst was stable under reaction conditions and could be recycled. Later, this catalyst was employed to transform glucose to mannose in aqueous solution as the first step to obtain mannitol, ${ }^{30}$ and POM overperformed bulk molybdenum oxide, which suffered complete leaching. Other closely related applications like tandem reactions for the production of alkyl lactates from ketohexoses ${ }^{31}$ in ethanol have been identified on bulk $\mathrm{MoO}_{3}$. Finally, niobium molybdates $\left(\mathrm{LiNbMoO}_{6}\right.$ and $\left.\mathrm{HNbMoO}_{6}\right)$ have been proposed as heterogeneous catalysts for the reaction. ${ }^{32}$

In this work, we study by first principles methods the epimerization reaction of glucose to mannose catalyzed by different Mo oxide species including two POMs: ${ }^{33}$ the Keggin ${ }^{34}$ $\mathrm{H}_{3} \mathrm{PMo}_{12} \mathrm{O}_{40}$ (with a set of different heteroatoms), the Dawson $\mathrm{H}_{6} \mathrm{P}_{2} \mathrm{Mo}_{18} \mathrm{O}_{62}$ clusters and the bulk material $\alpha-\mathrm{MoO}_{3}(010),{ }^{17}$ both as pristine and defective surfaces. We propose a mechanism for the Bilik reaction which explains the experimental observations and requires a single center. Finally, we have found that the reducibility of the Mo reaction centers is the unique descriptor for the activity of Mo oxides irrespective of their molecular or continuous nature.

\section{Computational methods}

Density Functional Theory (DFT) calculations were carried out with the 5.3.3 version of Vienna ab initio simulation package (VASP) for the molecular and continuous Mo-based catalyst. $^{35,36}$ The Perdew-Burke-Ernzerhof (PBE) functional ${ }^{37}$ was chosen to describe the exchange correlation energy. To correctly describe the on-site Coulomb interactions of localized $4 \mathrm{~d}$ electrons of molybdenum atoms the Hubbard $U$ correction, ${ }^{38} U_{\text {eff }}$, with a value of $3.5 \mathrm{eV}$ was introduced. The $U_{\text {eff }}$ value was optimized to reproduce the correct reaction energy and electron localization for the dissociative $\mathrm{H}_{2}$ adsorption. Gaussian smearing with smearing parameter $\sigma=0.1 \mathrm{eV}$ was used. The van der Waals contributions were accounted for with Grimme's semiempirical vdW-D2 correction. ${ }^{39}$ Projectoraugmented wave (PAW) pseudopotentials ${ }^{40}$ were used to replace the inner electrons. The kinetic cut-off energy to expand the valence electrons in plane-waves was set to $450 \mathrm{eV}$ and spin polarization was taken into account.

For all the molecules present in this study, including polyoxometalates, $\mathrm{H}_{n} \mathrm{XMo}_{12} \mathrm{O}_{40}$, a $19.5 \times 20 \times 20.5 \AA^{3}$ box was used. For the $\mathrm{H}_{6} \mathrm{P}_{2} \mathrm{Mo}_{18} \mathrm{O}_{62}$ cluster the simulation box volume was

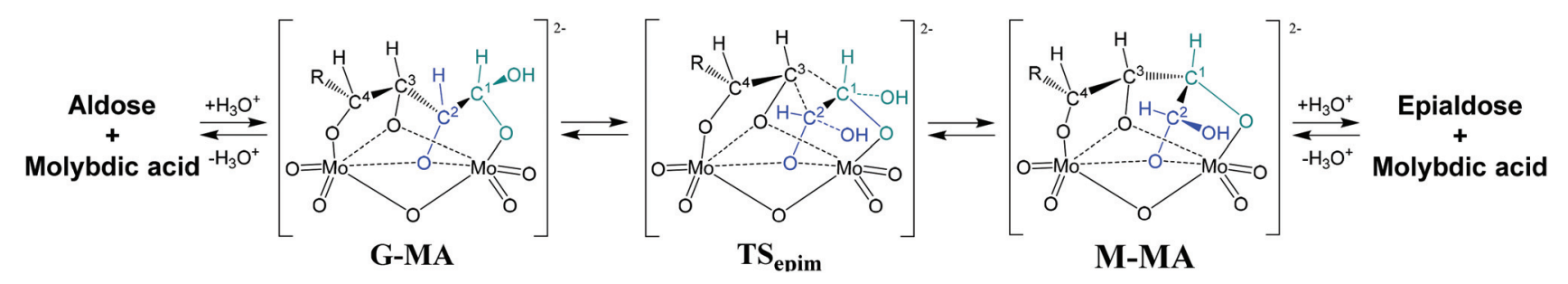

Scheme 2 Accepted mechanism for the epimerization of aldose pairs, Bilik reaction, catalyzed by molybdic acid. Adapted from ref. 23. 
increased to $25.5 \times 25 \times 24.5 \AA^{3}$. All cells were large enough to avoid the interaction between structures of neighboring unit cells, which were sampled at the Gamma point. All atoms were allowed to relax. Benchmark calculations for these settings were done with the Gaussian code obtaining very similar values, see Table SI1. $\dagger$ A slab model was used to test the reactivity on the $\alpha-\mathrm{MoO}_{3}(010)$ surface. A $(3 \times 3)$ supercell containing two bilayers with $3 \times 3 \times 1 k$-point sampling was considered. The upper bilayer and adsorbates were relaxed. A vacuum gap of $15 \AA$ was added between slabs. The use of asymmetric slabs causes spurious terms, which were avoided with the use of a dipole correction along the $z$ axis. ${ }^{41}$ The reaction path was tested both on the clean surface and on the terminal oxygen, $\mathrm{O}_{\mathrm{t}}$, defective surface with one vacancy per supercell. The climbing image nudged elastic band (CI-NEB) ${ }^{42,43}$ method was used to find the transition states, which were then refined with the improved dimer method (IDM). ${ }^{44,45}$ A vibrational analysis was applied to confirm all the minima and saddle points, and all energies were corrected by ZPVE. Solvation was included for $\left[\mathrm{H}_{3-n} \mathrm{PMo}_{12} \mathrm{O}_{40}\right]^{-n}, n$ between 0 and 3 , through the VASP-MGCM continuum $\operatorname{model}^{46,47}$ for an aqueous environment. To balance the charge of the Keggin cluster a cation with the equivalent valence $\mathrm{Rb}^{+1}, \mathrm{Sr}^{+2}$ or $\mathrm{Y}^{+3}$ was added to the system. To minimize spurious electrostatic interactions the distance between the anion and the cation was set to its maxima within the box. For the three systems the multiplicity of the POM was singlet. All the structures are published in the ioChem-BD database ${ }^{48}$ and can be retrieved in ref. 49 .

\section{Results}

The energy profile for the epimerization reaction starting by open glucose was calculated for the reaction on $\mathrm{H}_{3} \mathrm{PMo}_{12} \mathrm{O}_{40}$, $\mathrm{H}_{6} \mathrm{P}_{2} \mathrm{Mo}_{18} \mathrm{O}_{62}$ and the pristine and defective $\alpha-\mathrm{MoO}_{3}(010)$ surfaces. The structures of these compounds are shown in Fig. 1.

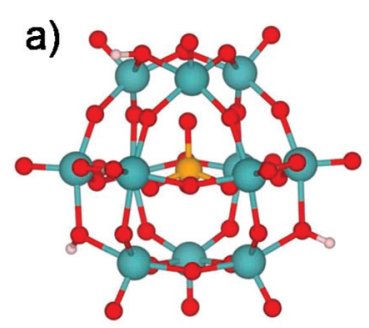

c)

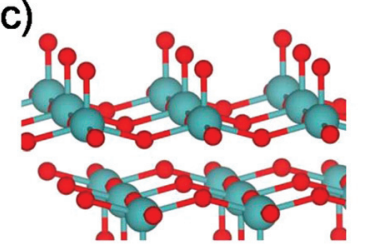

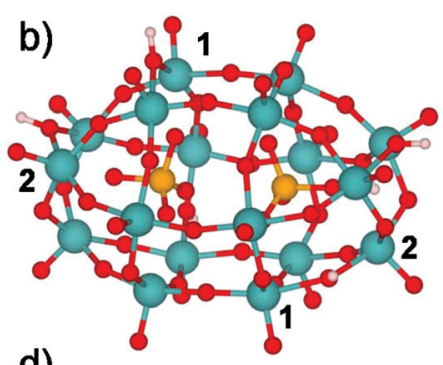

d)

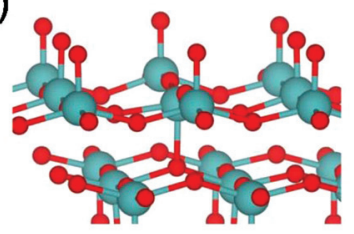

Fig. 1 Mo-Based systems where the Bilik reaction was investigated: (a) Keggin POM H $\mathrm{PMO}_{12} \mathrm{O}_{40}$; (b) Dawson $\mathrm{POM} \mathrm{H}_{6} \mathrm{P}_{2} \mathrm{Mo}_{18} \mathrm{O}_{62}$, two different types of Mo centers are indicated by 1 and 2; (c) $\alpha-\mathrm{MoO}_{3}$; (d) $\alpha-\mathrm{MoO}_{3-x}$. $\mathrm{Mo}$ atoms in green, $\mathrm{O}$ in red, $\mathrm{P}$ in orange and $\mathrm{H}$ in white.
All Mo centers of deprotonated $\left[\mathrm{PMo}_{12} \mathrm{O}_{40}\right]^{3-}$ and pristine $\alpha-\mathrm{MoO}_{3}(010)$ surfaces are equivalent whereas $\mathrm{H}_{6} \mathrm{P}_{2} \mathrm{Mo}_{18} \mathrm{O}_{62}$ has two different Mo environments (labelled as 1 and 2 in Fig. 1b). The molybdenum atoms in these three catalysts present a formal oxidation state of +6 . In the defective $\alpha-\mathrm{MoO}_{3-x}(010)$ surface two $\mathrm{Mo}^{+6}$ centers are reduced to $\mathrm{Mo}^{+5} .^{50-52}$

The coordination environments of the Mo centers in $\mathrm{H}_{3} \mathrm{PMo}_{12} \mathrm{O}_{40}$ do not allow the two center glucose coordination observed in glucose-dimolybdate complexes. ${ }^{23,27}$ Glucose coordinates to a single Mo, thus being similar to metal chlorides, ${ }^{10}$ which results in the mechanism and reaction profiles shown in Fig. 2. Detailed reaction energies and energy barriers are shown in Table SI2; $\uparrow$ and geometric parameters are provided in Table SI3. $\dagger$ Reaction free energy profiles including vibrational terms are shown in Fig. SI $2 . \dagger$

The overall reaction is almost thermoneutral, with the formation of mannose slightly favored by $0.09 \mathrm{eV}$. The barrier for non-catalyzed gas-phase epimerization of glucose to mannose is $1.37 \mathrm{eV}$. For $\mathrm{H}_{3} \mathrm{PMo}_{12} \mathrm{O}_{40}$, the open form of the glucose is dissociatively adsorbed on a Mo center (R1) through the $\mathrm{TS}_{\text {diss }}$. In the adsorbed state, $\mathrm{G}_{\mathrm{diss}}$, the hydroxyl group of $\mathrm{C}^{2}$ is bonded to a Mo center whereas the $\mathrm{C}^{1}$-aldehyde group interacts with the same Mo center forming a bidentate complex. This step is endothermic by $0.57 \mathrm{eV}$, with an activation barrier of $1.04 \mathrm{eV}$. Although glucose adsorption through other hydroxyl groups is possible, Fig. SI $3, \dagger$ it will not lead to the desired reactivity. The adsorbed glucose undergoes 1,2 C-shift (R2) through $\mathrm{TS}_{\text {epim }}$ where the $\mathrm{C}^{2}-\mathrm{C}^{3}$ bond is broken and $\mathrm{C}^{1}-\mathrm{C}^{3}$ is simultaneously formed. Concomitantly the $\mathrm{C}^{1}$ aldehyde transforms into an alkoxy group and $\mathrm{C}^{2}$ alkoxy into an aldehyde group. The corresponding final state is the dissociated mannose, $\mathbf{M}_{\mathrm{diss}}$, bonded to the Mo center through the oxygen of

a)

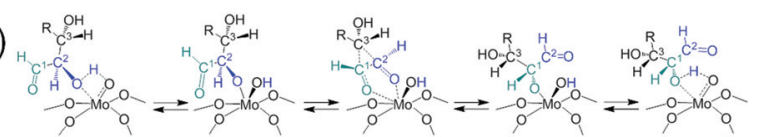

b)

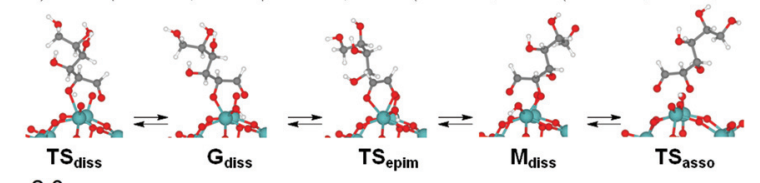

c)

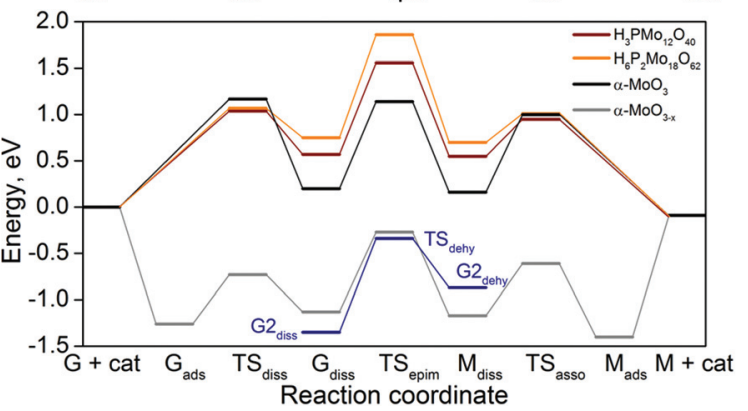

Fig. 2 (a) Proposed mechanism ${ }^{10}$ for the epimerization reaction on $\mathrm{H}_{3} \mathrm{PMO}_{12} \mathrm{O}_{40}$. (b) Optimized structures for reaction on $\mathrm{H}_{3} \mathrm{PMO}_{12} \mathrm{O}_{62}$. (c) Reaction profile for the Bilik reaction for glucose on $\mathrm{H}_{3} \mathrm{PMO}_{12} \mathrm{O}_{40}$, $\mathrm{H}_{6} \mathrm{P}_{2} \mathrm{MO}_{18} \mathrm{O}_{62}, \alpha-\mathrm{MoO}_{3}(010)$ and $\alpha-\mathrm{MoO}_{3-x}(010)$. Dehydration step on $\alpha-\mathrm{MoO}_{3-x}(010)$ is represented by the blue line. 
the alkoxy group of $\mathrm{C}^{1}$, with the aldehyde group of $\mathrm{C}^{2}$ also interacting with the same Mo center. The forward energy barrier is $0.99 \mathrm{eV}$. Finally, the proton is transferred back to $\mathbf{M}_{\text {diss }}$ driving the associative desorption (R3) of the mannose through $\mathrm{TS}_{\text {asso }}$. This process is exothermic by $0.64 \mathrm{eV}$ with a barrier of $0.40 \mathrm{eV}$.

The reaction mechanism starts with the open form of the glucose, but in water aldoses are mainly in their ring configurations. The presence of Mo-based compounds in reaction media can catalyze glucose opening, see Fig. SI4. $\dagger$

The Dawson cluster has two different Mo positions, Fig. 1b. Position 1 exhibits a better performance in both, binding and energy barriers for the reaction and, therefore, only the reactivity at this site will be discussed. The dissociative adsorption of glucose (R1) is endothermic by $0.75 \mathrm{eV}$, and the barrier is $1.07 \mathrm{eV}$. The 1,2 C-shift step (R2) is nearly thermoneutral, with $\mathbf{M}_{\text {diss }}$ formation slightly favored by $0.05 \mathrm{eV}$. The energy barrier is $1.10 \mathrm{eV}$ and the associative desorption of mannose (R3) is exothermic, $-0.79 \mathrm{eV}$, with a small barrier of $0.31 \mathrm{eV}$.

We extended the reaction path calculated for POMs to the bulk $\alpha-\mathrm{MoO}_{3}$ on the pristine and defective (010) surfaces. ${ }^{15-18,21}$ The mechanism on the regular surface follows that found for POMs. However, the first step is only slightly endothermic by $0.20 \mathrm{eV}$, with a relatively low barrier of $1.17 \mathrm{eV}$. The reaction energy for the epimerization step is $-0.04 \mathrm{eV}$, practically thermoneutral, and the forward activation energy is $0.94 \mathrm{eV}$. The desorption of mannose is exothermic, with a reaction energy of $-0.24 \mathrm{eV}$ and a barrier of $0.85 \mathrm{eV}$. Oxides might lose oxygen and thus the reaction on the reduced surface needs to be investigated. Unlike the $\mathrm{Mo}^{+6}$ centers, glucose adsorption on the $\mathrm{Mo}^{+5}$ center of $\alpha-\mathrm{MoO}_{3-x}(010)$ through the $-\mathrm{OH}$ group of $\mathrm{C}^{2}$ is non-dissociative, and it is highly exothermic, $-1.26 \mathrm{eV}$. The adsorbed glucose is dissociated by transferring the hydrogen atom of the interacting $-\mathrm{OH}$ group to a neighboring $\mathrm{O}_{\mathrm{t}}$. This $-\mathrm{OH}$ dissociation is slightly endothermic by $0.14 \mathrm{eV}$. The energy barrier to this step is $0.53 \mathrm{eV}$. Most likely, this step corresponds to a proton coupled electron transfer as the images along the path belong to two different electron localizations. Again, the 1,2 C-shift step is close to thermoneutral, $-0.04 \mathrm{eV}$, and its barrier is $0.87 \mathrm{eV}$. After this step, the hydrogen is transferred back from the surface to the mannose oxygen bonded to the Mo center. This process is exothermic by $0.23 \mathrm{eV}$ with an energy barrier of $0.55 \mathrm{eV}$. Desorption of the mannose molecule formed in this step is highly endothermic, with a reaction energy of $1.40 \mathrm{eV}$. However, defective $\mathrm{MoO}_{3-x}$ has been reported as an active catalyst for the hydrodeoxygenation (HDO) of oxygenated compounds as alcohols and polyalcohols through the breaking of C-O bonds. ${ }^{15,16,18}$ Glucose has five $-\mathrm{OH}$ groups that could undergo HDO. We have calculated the dehydration step for the $-\mathrm{O}_{5} \mathrm{H}$ group of glucose obtaining an energy barrier of $1.01 \mathrm{eV}$, Fig. SI5. $\dagger$ Similar values are expected for the other $-\mathrm{OH}$ groups. This result compromises the selectivity for epimerization on the defective $\mathrm{MoO}_{3-x}(010)$ surface towards dehydrated compounds and discards it as a catalyst for the reaction.
Theory also explains why in experiments vicinal hydroxyl groups have an important effect on the epimerization reaction. ${ }^{23}$ In our path, the relevance of the $\mathrm{C}^{2}$ alcohol group is evident, since it takes part directly in the mechanism, as glucose adsorbs on the Mo center through this alcohol group and its transformation into a ketone allows the chain rearrangement. In order to study the influence of $-\mathrm{O}^{3} \mathrm{H}$ and $-\mathrm{O}^{4} \mathrm{H}$ groups, we calculated the intermediates and transition states for the 1,2 C-shift step for glucoses without these groups on $\mathrm{H}_{3} \mathrm{PMo}_{12} \mathrm{O}_{40}$. The energy profile of this step for three systems is shown in Fig. SI6. $\dagger$ The presence of $-\mathrm{O}^{3} \mathrm{H}$ and $-\mathrm{O}^{4} \mathrm{H}$ has a weak influence on the adsorption energy of molecules; they are between $0.47-0.57 \mathrm{eV}$ for the three systems. However, the energy barriers increase from $0.99 \mathrm{eV}$, with glucose, to $1.08 \mathrm{eV}$ without $-\mathrm{O}^{4} \mathrm{H}$ and to $1.23 \mathrm{eV}$ without $-\mathrm{O}^{3} \mathrm{H}$, in agreement with the experiments with molybdates, ${ }^{24}$ Table SI $4 \dagger$ Although these $-\mathrm{OH}$ groups do not play a direct role in the interaction with the POM, the presence of $-\mathrm{O}^{3} \mathrm{H}$ has a great influence on the stabilization of the transition state. In the adsorbed glucose the $\mathrm{C}^{3}-\mathrm{O}^{3}$ bond distance is $1.413 \AA$. This distance is reduced to $1.350 \AA$ at the transition state, indicating the formation of a partial double bond $\mathrm{C}^{3}=-\mathrm{O}^{3} \mathrm{H}$ that stabilizes the transition state. This effect could also be present in the reaction catalyzed by molybdates. In adsorbed glucose a hydrogen bond is formed between $-\mathrm{O}^{3} \mathrm{H}$ and $-\mathrm{O}^{4} \mathrm{H}$ with a distance of $2.432 \AA$. In the transition state structure, $\mathrm{C}^{3}$ has partial sp ${ }^{2}$ geometry reducing this distance to $2.259 \AA$, thus stabilizing the structure. In adsorbed glucose without $-\mathrm{O}^{4} \mathrm{H}$, the $-\mathrm{O}^{3} \mathrm{H}$ group forms a strong hydrogen bond with the $-\mathrm{O}^{5} \mathrm{H}$ group with a distance of $1.800 \AA$. In contrast, for glucose, this distance increases to $2.000 \AA$ at the transition state due to the geometry change in $\mathrm{C}^{3}$, increasing the activation energy. Thus, computed results explain previous experimental observations for molybdates.

The reaction is carried out in aqueous solution, and we have investigated the influence of the solvent only for the $\mathrm{H}_{3} \mathrm{PMo}_{12} \mathrm{O}_{40}$ system. In gas-phase, the dissociative adsorption of sugars involves high energy barriers, but the presence of water molecules acting as hydrogen shuttles reduces this barrier to 0.54 and $0.55 \mathrm{eV}$ for glucose and mannose, respectively, Fig. SI7. $\dagger$ In addition, in aqueous solution the Keggin cluster has a high solubility and is fully dissociated. ${ }^{53}$ We have investigated how deprotonation and solvation affects the 1,2 C-shift. Binding energy for dissociated glucose and mannose and the energy barrier for this elementary step on solvated $\left[\mathrm{H}_{n} \mathrm{Mo}_{12} \mathrm{O}_{40}\right]^{3-n}$ are shown in Fig. 3 and Table SI5. $\dagger$ The dissociative binding energy of glucose and mannose on solvated $\mathrm{H}_{3} \mathrm{PMO}_{12} \mathrm{O}_{40}$ is not affected by the presence of water. However, the energy barrier for 1,2 C-shift is reduced by $0.24 \mathrm{eV}$. This is due to the polarity of water that stabilizes the transition state structure. Binding and activation energies for 1,2 C-shift increase almost linearly with the overall charge of the deprotonated POMs, Fig. SI8, $\uparrow$ the binding energy ranging from 0.57 to $1.05 \mathrm{eV}$ and the activation barrier from 0.79 to $1.00 \mathrm{eV}$. The presence of a polar solvent smoothed this effect by the stabilization of the charge. The completely deprotonated POM, 


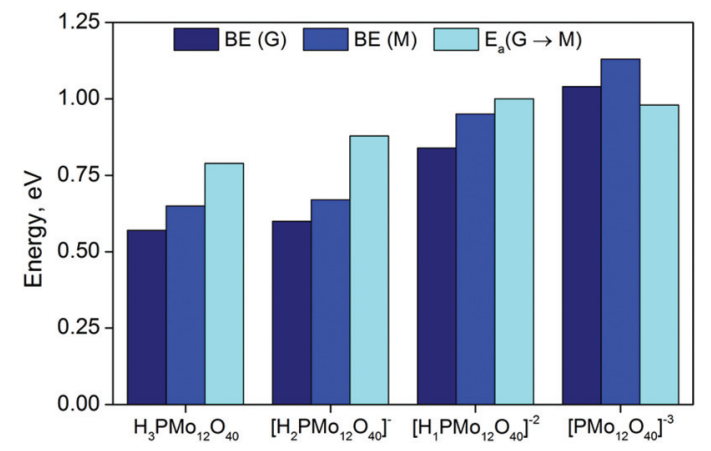

Fig. 3 Charge effects in the binding, $\mathrm{BE}$, and activation energies, $E_{\mathrm{a}}$ both in eV, for the 1,2 C-shift step at the Keggin cluster including solvation effects. Solvated POMs and solvated open form of glucose as reference.

$\left[\mathrm{PMo}_{12} \mathrm{O}_{40}\right]^{-3}$, has an energy barrier for the epimerization elementary step of $1.00 \mathrm{eV}$, very similar to the barrier calculated for $\mathrm{H}_{3} \mathrm{PMo}_{12} \mathrm{O}_{40}$ in gas phase. Geometrical details are shown in Table SI6. $\dagger$ In order to have a better understanding of the role of the solvent in this step we performed a set of calculations with one and two explicit water molecules, Fig. SI9 and Table SI7. $\dagger$ One water molecule was adsorbed on the $-\mathrm{O}_{\mathrm{t}} \mathrm{H}$ group bonded to the Mo reactive center through a hydrogen bond, the water molecule being the hydrogen donor. The presence of this water molecule reduces the activation energy by $0.12 \mathrm{eV}$. This water molecule weakens the $\mathrm{O}_{\mathrm{t}}-\mathrm{Mo}$ bond allowing a better stabilization of the transition state. Alternatively, if the water molecule is placed between $-\mathrm{O}_{3} \mathrm{H}$ and $-\mathrm{O}_{4} \mathrm{H}$, being the hydrogen acceptor of $-\mathrm{O}_{3} \mathrm{H}$ and the donor for $-\mathrm{O}_{4} \mathrm{H}$, the activation energy is reduced by $0.10 \mathrm{eV}$ as water assists the formation of the partial double bond $\mathrm{C}^{3}=-\mathrm{O}^{3} \mathrm{H}$. We also calculated the system including simultaneously these two water molecules, and then the activation energy is reduced by $0.19 \mathrm{eV}$, and thus the value is very similar to that calculated with the solvation VASP-MGCM model.

Finally, we tested the influence of the heteroatom in the $\mathrm{H}_{n} \mathrm{XMo}_{12} \mathrm{O}_{40}(\mathrm{X}=\mathrm{P}, \mathrm{As}, \mathrm{Si}, \mathrm{Ge})$ in the 1,2 C-shift elementary step. It is reported that the heteroatom does not participate directly in the reactivity, but these heteroatoms present different formal charges and thus induce different charge distribution over the POM structure which finely tunes the redox properties of the POM framework. ${ }^{54,55}$ Intermediates and transition states on $\mathrm{H}_{n} \mathrm{XMo}_{12} \mathrm{O}_{40}(\mathrm{X}=\mathrm{S}, \mathrm{P}, \mathrm{As}, \mathrm{Si}, \mathrm{Ge})$ for this elementary step have been calculated. Energy profiles for this step are shown in Fig. SI10. $\dagger$ As is shown in Table 1 the heteroatom has a relatively mild influence. Binding energies range from 0.51 to $0.67 \mathrm{eV}$ for glucose, and between 0.49 and $0.62 \mathrm{eV}$ for mannose, see Tables SI8 and SI9. $\dagger$ Energy barriers for the glucose to mannose epimerization are between 0.95 and $1.07 \mathrm{eV}$. Binding and activation energies increase with the number of valence electrons in the heteroatom, and, for a given valence with the heteroatom size.

The lowest energy barriers for the epimerization step are on solid $\alpha-\mathrm{MoO}_{3}(010)$, both pristine and defective surfaces. This
Table 1 Binding energy, $\mathrm{BE}$, in $\mathrm{eV}$, of glucose and mannose on $\mathrm{H}_{n} \mathrm{XMO}_{12} \mathrm{O}_{40}$ (relative to gas-phase glucose and POM), activation energy, $E_{\mathrm{a}}, \mathrm{eV}$, for 1,2 C-shift, and Bader analysis of the charge transfer from the heteroanion to the $\mathrm{Mo}_{12} \mathrm{O}_{36}$ skeleton

\begin{tabular}{|c|c|c|c|c|c|c|}
\hline $\mathrm{X}$ & $\mathrm{BE}(\mathrm{G})$ & $\mathrm{BE}(\mathrm{M})$ & $\begin{array}{c}E_{\mathrm{a}} \mathrm{TS}_{\text {epim }} \\
(\mathrm{G} \rightarrow \mathrm{M})\end{array}$ & $\begin{array}{l}\text { Formal } \\
\text { charge } \\
\mathrm{XO}_{4}{ }^{n-}\end{array}$ & $\begin{array}{l}\text { Bader } \\
\text { charge } \\
\mathrm{XO}_{4}{ }^{n-}\end{array}$ & $\begin{array}{c}\text { Transferred } \\
\text { charge }\end{array}$ \\
\hline $\mathrm{S}$ & 0.51 & 0.49 & 0.95 & -2 & -1.61 & -0.39 \\
\hline $\mathrm{P}$ & 0.57 & 0.55 & 0.99 & -3 & -2.23 & -0.77 \\
\hline As & 0.61 & 0.57 & 1.00 & -3 & -2.19 & -0.89 \\
\hline $\mathrm{Si}$ & 0.65 & 0.59 & 1.02 & -4 & -2.72 & -1.28 \\
\hline G & 0.67 & 0.62 & 1.07 & -4 & -2.69 & -1.31 \\
\hline
\end{tabular}

energy barrier on $\alpha-\mathrm{MoO}_{3-x}(010)$ is $0.09 \mathrm{eV}$ lower than that on $\alpha-\mathrm{MoO}_{3}(010)$ and $0.16 \mathrm{eV}$ lower than that on $\mathrm{H}_{3} \mathrm{PMo}_{12} \mathrm{O}_{40}$. However the adsorption energies of glucose and mannose on $\alpha-\mathrm{MoO}_{3-x}(010)$ are highly exothermic, -1.26 and $-1.40 \mathrm{eV}$ respectively, and therefore, the desorption of glucose/mannose is the most energy demanding step. $\alpha-\mathrm{MoO}_{3}(010)$, $\mathrm{H}_{3} \mathrm{PMo}_{12} \mathrm{O}_{40}$, and $\mathrm{H}_{6} \mathrm{P}_{2} \mathrm{Mo}_{18} \mathrm{O}_{62}$ have similar energy barriers for the dissociative adsorption of the glucose/mannose pair, Fig. 2. However, the binding energies of dissociated molecules and the energy barrier for the epimerization step increase in the order: $\alpha-\mathrm{MoO}_{3}(010)<\mathrm{H}_{3} \mathrm{PMo}_{12} \mathrm{O}_{40}<\mathrm{H}_{6} \mathrm{P}_{2} \mathrm{Mo}_{18} \mathrm{O}_{62}$.

As stability seems to be an issue for the Mo-based catalyst, we have investigated the thermodynamic stability of crystalline structures in terms of their cohesive energy, i.e. the energy required to separate the crystalline material into isolated molecular units. We have calculated the cohesive energy for $\left[\mathrm{PMo}_{12} \mathrm{O}_{40}\right]^{-3}$, the POM species present in aqueous solution, and for bulk $\alpha-\mathrm{MoO}_{3}$ in order to compare their stabilities. The monomer molybdic acid, $\mathrm{H}_{2} \mathrm{MoO}_{4}$, was used as a reference, as it is the smallest molybdenum compound present in aqueous solution. The dissolution of $\mathrm{MoO}_{3}$ and $\left[\mathrm{PMo}_{12} \mathrm{O}_{40}\right]^{-3}$ can be written as:

$$
\begin{gathered}
n \mathrm{MoO}_{3}+n \mathrm{H}_{2} \mathrm{O} \rightarrow n \mathrm{H}_{2} \mathrm{MoO}_{4} \\
{\left[\mathrm{PMo}_{12} \mathrm{O}_{40}\right]^{-3}+12 \mathrm{H}_{2} \mathrm{O} \rightarrow 12 \mathrm{H}_{2} \mathrm{MoO}_{4}+\mathrm{PO}_{4}{ }^{3-}}
\end{gathered}
$$

The calculated cohesive energies are $1.06 \mathrm{eV}$ per $\mathrm{MoO}_{3}$ for bulk $\alpha-\mathrm{MoO}_{3}$, and $1.78 \mathrm{eV}$ per $\mathrm{MoO}_{3}$ for $\left[\mathrm{PMo}_{12} \mathrm{O}_{40}\right]^{-3}$. This higher thermodynamic stability of the POM is due to the electrostatic interactions between the encapsulated anion and the $\mathrm{Mo}_{12} \mathrm{O}_{36}$ framework that makes it stable against leaching in aqueous solution. The same strategy is used for the stability of layered niobium molybdates where the presence of $\mathrm{Li}^{+}$or $\mathrm{H}^{+}$ atoms in the interlayer region has a similar effect as the encapsulated ion in POMs, avoiding leaching in aqueous solution by improving electrostatics. ${ }^{32}$

\section{Discussion: descriptor analysis}

Direct deprotonation of the POM affects the MoO-framework charge and similarly POMs with different heteroatoms present slightly different MoO-framework charges due to the charge 
transfer between the anions and the $\mathrm{MoO}_{6}$ POM units, see Table 1 and Table SI10. $\dagger$ Binding energies and the energy barrier for the 1,2 C-shift increase linearly with the POM MoOframework charge, Fig. SI11. $\dagger$ The reduction potentials follow a similar trend as they decrease linearly with the degree of deprotonation. ${ }^{55-57}$

Analyzing our reaction network we find that during 1,2 $\mathrm{C}$-shift the $\mathrm{C}^{1}$ aldehyde group is transformed into an alkoxy group and a $\mathrm{C}^{2}$ alkoxy group in an aldehyde group allowing the carbon chain rearrangement. Thus, the large electronic rearrangement in this step has been investigated by calculating the charge density difference of the $\mathrm{TS}_{\text {epim }}$ with respect to the $\left[\mathrm{C}_{6} \mathrm{H}_{11} \mathrm{O}_{6}\right]^{-}$anion and the protonated POM. This difference is shown in Fig. 4a illustrating the charge depletion from the lone pair of the isolated glucose and accumulation at the Mo center. This result indicates that Mo reducibility ${ }^{58,59}$ is the controlling factor in the reaction. However, the direct calculation of single atom reducibility on the surface of $\mathrm{MoO}_{3}$ is elusive and thus alternatives are needed.

Iglesia et al. have proposed the $\mathrm{H}$-atom addition energy (HAE) as the descriptor for $\mathrm{C}-\mathrm{H}$ activation for methanol oxidation on Keggin clusters ${ }^{60,61}$ (other geometric and electronic parameters are discussed in descriptors ${ }^{58,59}$ in Table SI11 $\dagger$ ). We used this parameter for glucose epimerization. HAE is calculated as the energy to add a hydrogen atom to an oxygen on the catalyst:

$$
\mathrm{HAE}=E_{\text {cat }+\mathrm{H}^{\cdot}}-E_{\text {cat }}
$$

This descriptor combines both the reducibility of the metal center, by the addition of an electron, and the basicity of the oxygen atom, as a proton is retained on a neighboring oxygen. To minimize the influence of the different basicities of Mo-neighboring $\mathrm{O}$ atoms several $\mathrm{O}$ atoms were sampled, always ensuring that electron localization occurs at the desired center. The catalysts in the analysis were $\mathrm{H}_{n} \mathrm{XMo}_{12} \mathrm{O}_{40}$ (X: S, P, As, Si, Ge), $\mathrm{H}_{6} \mathrm{P}_{2} \mathrm{Mo}_{18} \mathrm{O}_{62}, \alpha-\mathrm{MoO}_{3}(010)$ and $\alpha-\mathrm{MoO}_{3-x}(010)$. The results shown in Fig. $4 \mathrm{~b}$ and $\mathrm{c}$ indicate that both the reactant (product) adsorption and the activation energy for the 1,2 C-shift elementary step depend on the HAE.

In addition, for POMs the reducibility can be extracted from the previous calculations as follows:

$$
\operatorname{Red}=\operatorname{HAE}-\left(E_{\text {cat }+\mathrm{H}^{+}}-E_{\text {cat }}\right)
$$

where the second term eliminates the contribution from the basicity. As is shown in Fig. SI12 $\uparrow$ adsorption and activation energies correlate with the reducibility for the six studied POMs, showing how a higher reducibility results in a lower energy barrier. Thus, the redox properties of the catalyst are ultimately responsible for catalytic behavior, and reducibility is the single descriptor that correctly defines adsorption and activation energies for this process. The electronic descriptor has two advantages: (i) it maps the geometry of the Mo-O distance (Fig. SI13†) and more importantly (ii) it is very easy to a)
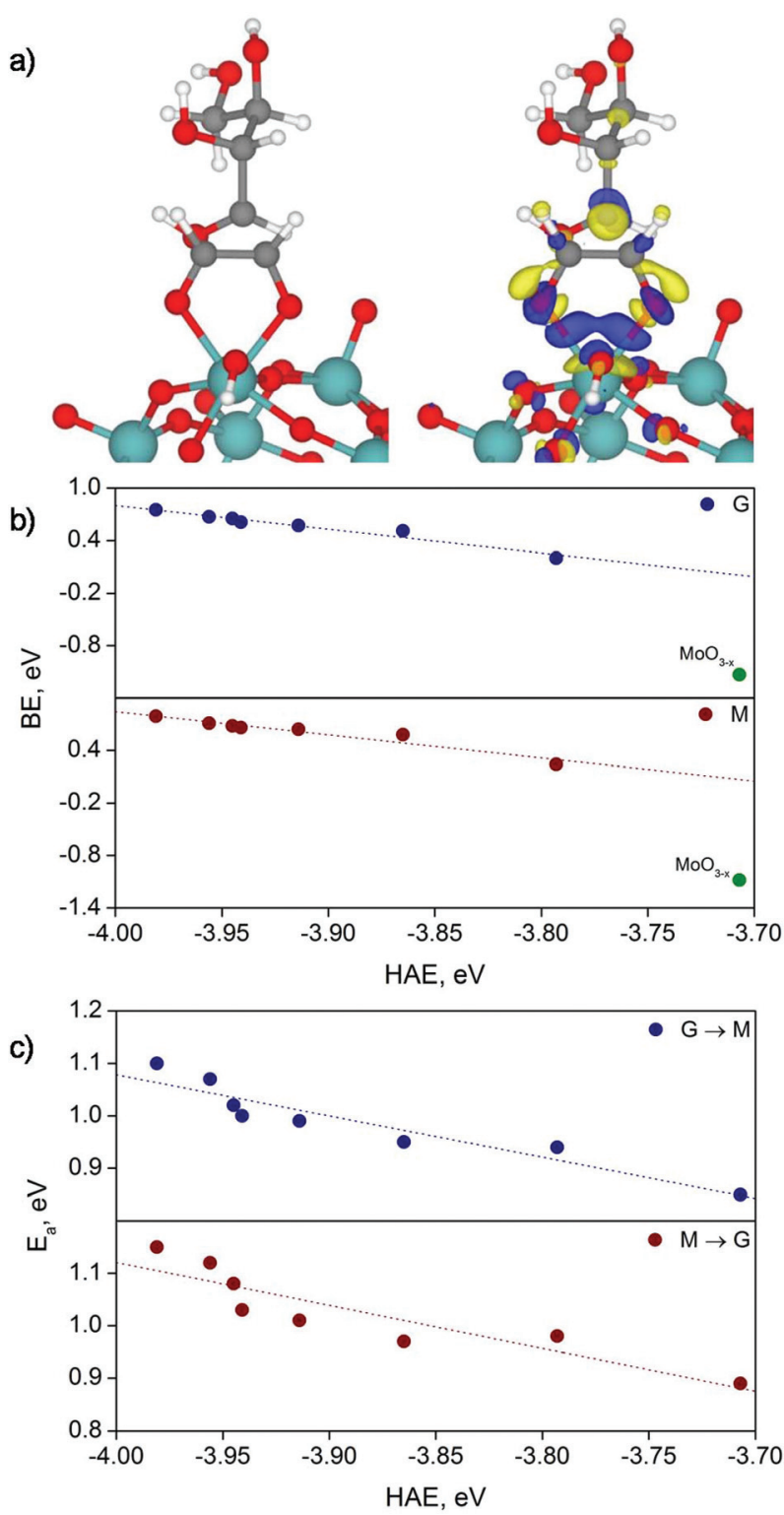

Fig. 4 (a) Structure of $\mathrm{TS}_{\text {epim }}$ for $\mathrm{H}_{3} \mathrm{PMO}_{12} \mathrm{O}_{40}$ (left) and $\mathrm{TS}_{\text {epim }}$ charge density difference (right). The charge density difference was calculated with respect to the anion $\left[\mathrm{C}_{6} \mathrm{H}_{11} \mathrm{O}_{6}\right]^{-}$and cation $\left(\mathrm{H}_{4} \mathrm{PMo}_{12} \mathrm{O}_{40}\right)^{+}$at the $\mathrm{TS}_{\text {epim }}$ geometry; same color code as Fig. 1. Blue color means depletion of charge density and yellow color means accumulation. (b) Binding energy, $\mathrm{BE}$, of dissociated glucose and mannose as a function of $\mathrm{HAE}$. $E_{\mathrm{ads}}(\mathrm{G})=$ $-2.72 \mathrm{HAE}-10.08 \mathrm{eV}, R^{2}=0.96, \mathrm{MAE}=0.03 \mathrm{eV} . E_{\mathrm{ads}}(\mathrm{M})=-2.65 \mathrm{HAE}-$ $9.74 \mathrm{eV}, R^{2}=0.93, \mathrm{MAE}=0.03 \mathrm{eV}$. Adsorption on defective $\mathrm{MoO}_{3-x}(010)$ surface is not included in the fittings. (c) Activation energy, $E_{\mathrm{a}}$ of $\mathrm{TS}_{\text {epim }}$ as a function of HAE. $E_{\mathrm{a}}(\mathrm{G} \rightarrow \mathrm{M})=-0.79 \mathrm{HAE}-2.06 \mathrm{eV}, R^{2}=0.88, \mathrm{MAE}=$ $0.02 \mathrm{eV} . E_{\mathrm{a}}(\mathrm{M} \rightarrow \mathrm{G})=-0.81 \mathrm{HAE}-2.13 \mathrm{eV}, R^{2}=0.81, \mathrm{MAE}=0.03 \mathrm{eV}$.

measure experimentally as cyclic voltammetry could easily determine the reducibility. ${ }^{62}$

A microkinetic model was built in order to obtain the analytical equation for the reaction rate. The energies for the adsorption and 1,2 C-shifts are obtained from the linear fittings in Fig. $4 \mathrm{~b}$ and c. From the reaction profile (Fig. 2) the epimeriza- 


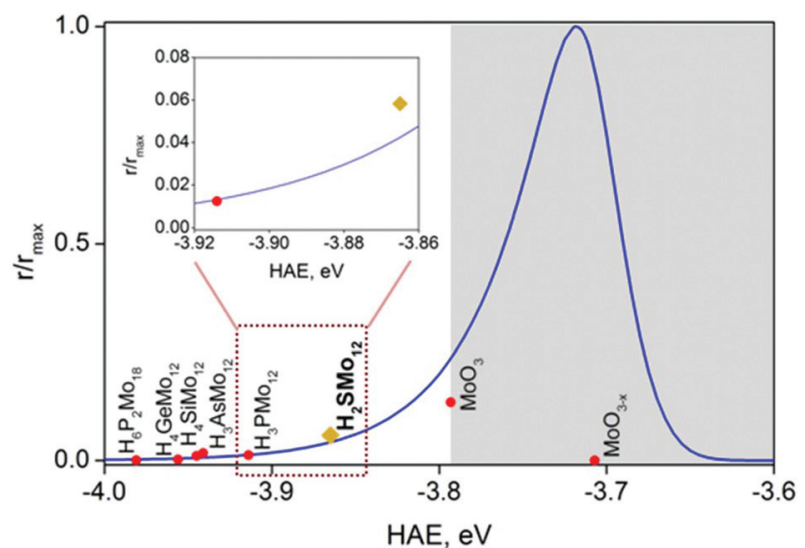

Fig. 5 Volcano plot of the normalized reaction rate as a function of the HAE. Conditions: $T=100{ }^{\circ} \mathrm{C},[\mathrm{G}]=0.90 \mathrm{M},[\mathrm{M}]=0.10 \mathrm{M}$. Red points mark the calculated rate with eqn (5) for the catalyst used in the analysis. Catalysts in the shadow area present drawbacks for epimerization reaction.

tion step is the rate-determining step and using the quasi-equilibrium approximation the reaction rate can be expressed as:

$$
r=k_{2} K_{G}[G]\left(1-\frac{[M]}{K_{\text {global }}[G]}\right) \frac{1}{1+K_{G}[G]+\frac{1}{K_{M}}[M]}
$$

where $K_{i}$ are the adsorption constants for glucose and mannose, $i=\mathrm{G}, \mathrm{M}$; $k_{2}$ is the coefficient for 1,2 C-shift (R2) starting from glucose, $K_{\text {global }}$ is the constant for the epimerization reaction, and $[\mathrm{M}]$ and $[\mathrm{G}]$ are the corresponding concentrations of glucose and mannose. Dissociative adsorption and 1,2 C-shift energy barrier can be written in terms of the HAE. At $100{ }^{\circ} \mathrm{C}$, for $[\mathrm{G}]_{i}=1 \mathrm{M}$ and a conversion of $10 \%$ the reaction rate shows a volcano shape with the maximum placed in HAE $=-3.72 \mathrm{eV}$, with TOF $=10.1 \mathrm{~s}^{-1}$. In Fig. 5 the normalized reaction rate is plotted as a function of the HAE. The calculated rate for the defective surface is displaced from the rate fitting, as its adsorption energy does not adjust to the linear fitting. Pristine and defective $\mathrm{MoO}_{3}$ surfaces are placed in a shadow zone, indicating that they present drawbacks for epimerization reaction; low stability in aqueous solution ${ }^{30-32}$ or selectivity. Therefore, $\mathrm{H}_{2} \mathrm{SMo}_{12} \mathrm{O}_{40}$ is the best catalyst for epimerization, and overperforming the activity of $\mathrm{H}_{3} \mathrm{PMo}_{12} \mathrm{O}_{40}$. Calculated apparent activation energy using the reaction rate obtained from eqn (5), for $\mathrm{H}_{3} \mathrm{PMo}_{12} \mathrm{O}_{40}$ is $1.04 \mathrm{eV}$, in good agreement with experimental value: $0.99 \pm 0.04 \mathrm{eV}^{19}$ The apparent activation energy calculated for $\mathrm{H}_{2} \mathrm{SMo}_{12} \mathrm{O}_{40}$ is $1.00 \mathrm{eV}$, Fig. SI14. $\dagger$ The plot shows a narrow zone of reducibility where the Mo-based catalysts are active for epimerization. POMs are placed in the upper end of this zone and, therefore, a more active catalyst could be developed.

\section{Conclusions}

We have identified the mechanism behind the epimerization, the Bilik reaction, in the glucose/mannose pair on Mo-con- taining catalysts. The mechanism encompasses the adsorption of the aldose, the 1,2 C-shift and the recombination for desorption of the product. The same mechanism is valid for molecular and surface Mo oxides and no significant differences are found for the heteroatom or the curvature of the surface. The descriptor for the reaction corresponds to the reducibility of the Mo atoms on the surface/molecular catalyst that plays a crucial role in the 1,2 C-shift. When the reaction is written in terms of the HAE-descriptor ( $\mathrm{H}$ addition energy) it is possible to optimize the composition thus indicating the most active system. The molecular catalyst also presents an excellent behavior in terms of the stability due to the electrostatic interaction between the heteroatom anion and the $\mathrm{MoO}_{x}$ shell. The bulk oxide shows a low cohesive energy. However, electrostatic interactions between the charged heteroatom unit and the $\mathrm{Mo}_{12} \mathrm{O}_{36}$ layer are larger which indicates the preeminent stability of the molecular catalyst. Finally, a more active $\mathrm{POM}, \mathrm{H}_{2} \mathrm{SMo}_{12} \mathrm{O}_{40}$, is proposed.

\section{Conflicts of interest}

There are no conflicts to declare.

\section{Acknowledgements}

The authors acknowledge the Spanish Ministerio de Economía y Competitividad (MINECO) for financial support (CTQ 201568770-R, Severo Ochoa Excellence Accreditation 2014-2018 SEV-2013-0319, and Severo Ochoa predoctoral grant SVP-2014068237). In addition, we thank BSC-RES for providing computational resources.

\section{References}

1 Y.-C. Park, E. J. Oh, J.-H. Jo, Y.-S. Jin and J.-H. Seo, Curr. Opin. Biotechnol., 2016, 37, 105-113.

2 I. Delidovich and R. Palkovits, ChemSusChem, 2016, 9, 547561.

3 M. E. Tanner, Acc. Chem. Res., 2002, 35, 237-246.

4 J. Samuel and M. E. Tanner, Nat. Prod. Rep., 2002, 19, 261277.

5 S.-C. Lu and S.-C. Lin, Enzyme Microb. Technol., 2012, 50, 65-70.

6 S. J. Angyal, Carbohydr. Res., 1997, 300, 279-281.

7 T. Tanase, F. Shimizu, S. Yano and S. Yoshikawa, J. Chem. Soc., Chem. Commun., 1986, 1001-1003.

8 T. Tanase, F. Shimizu, M. Kuse, S. Yano, M. Hidai and S. Yoshikawa, Inorg. Chem., 1988, 27, 4085-4094.

9 A. M. Peres and E. A. Macedo, Ind. Eng. Chem. Res., 1997, 36, 2816-2820.

10 H. Nguyen, V. Nikolakis and D. G. Vlachos, ACS Catal., 2016, 6, 1497-1504. 
11 R. Bermejo-Deval, R. Gounder and M. E. Davis, ACS Catal., 2012, 2, 2705-2713.

12 R. Bermejo-Deval, M. Orazov, R. Gounder, S.-J. Hwang and M. E. Davis, ACS Catal., 2014, 4, 2288-2297.

13 W. R. Gunther, Y. Wang, Y. Ji, V. K. Michaelis, S. T. Hunt, R. G. Griffin and Y. Roman-Leshkov, Nat. Commun., 2012, 3, 2122.

14 W. R. Gunther, Q. Duong and Y. Román-Leshkov, J. Mol. Catal. A: Chem., 2013, 379, 294-302.

15 T. Prasomsri, T. Nimmanwudipong and Y. Roman-Leshkov, Energy Environ. Sci., 2013, 6, 1732-1738.

16 T. Prasomsri, M. Shetty, K. Murugappan and Y. RomanLeshkov, Energy Environ. Sci., 2014, 7, 2660-2669.

17 M. Rellán-Piñeiro and N. López, ChemSusChem, 2015, 8, 2231-2239.

18 V. Zacharopoulou, E. S. Vasiliadou and A. A. Lemonidou, Green Chem., 2015, 17, 903-912.

19 F. Ju, D. VanderVelde and E. Nikolla, ACS Catal., 2014, 4, 1358-1364.

20 T. L. Lohr, A. R. Mouat, N. M. Schweitzer, P. C. Stair, M. Delferro and T. J. Marks, Energy Environ. Sci., 2017, 10, 1558-1562.

21 T. Choksi and J. Greeley, ACS Catal., 2016, 6, 7260-7277.

22 V. Bilik, Chem. Zvesti, 1972, 26, 183-186.

23 L. Petruš, M. Petrušová and Z. Hricovíniová, in Glycoscience: Epimerisation, Isomerisation and Rearrangement Reactions of Carbohydrates, ed. A. E. Stütz, Springer Berlin Heidelberg, Berlin, Heidelberg, 2001, pp. 15-41.

24 M. L. Hayes, N. J. Pennings, A. S. Serianni and R. Barker, J. Am. Chem. Soc., 1982, 104, 6764-6769.

25 J. E. Godfrey and J. M. Waters, Cryst. Struct. Commun., 1975, $4,5-8$

26 G. E. Taylor and J. M. Waters, Tetrahedron Lett., 1981, 22, 1277-1278.

27 M. Matulova and V. Bilik, Chem. Pap., 1990, 44, 257-265.

28 B. K. Chethana, D. Lee and S. H. Mushrif, J. Mol. Catal. A: Chem., 2015, 410, 66-73.

29 A. Cybulski, B. F. M. Kuster and G. B. Marin, J. Mol. Catal., 1991, 68, 87-103.

30 G. M. Lari, O. G. Gröninger, Q. Li, C. Mondelli, N. López and J. Pérez-Ramírez, ChemSusChem, 2016, 9, 3407-3418.

31 M. Orazov and M. E. Davis, Proc. Natl. Acad. Sci. U. S. A., 2015, 112, 11777-11782.

32 A. Takagaki, S. Furusato, R. Kikuchi and S. T. Oyama, ChemSusChem, 2015, 8, 3769-3772.

33 М. Т. Pope and A. Müller, Angew. Chem., Int. Ed. Engl., 1991, 30, 34-48.

34 J. F. Keggin, Proc. R. Soc. London, Ser. A, 1934, 144, 75-100.

35 G. Kresse and J. Furthmuller, Comput. Mater. Sci., 1996, 6, 15-50.

36 G. Kresse and J. Furthmueller, Phys. Rev. B: Condens. Matter Mater. Phys., 1996, 54, 11169-11186.

37 J. P. Perdew, K. Burke and M. Ernzerhof, Phys. Rev. Lett., 1996, 77, 3865-3868.
38 S. L. Dudarev, G. A. Botton, S. Y. Savrasov, C. J. Humphreys and A. P. Sutton, Phys. Rev. B: Condens. Matter Mater. Phys., 1998, 57, 1505-1509.

39 S. Grimme, J. Comput. Chem., 2006, 27, 1787-1799.

40 G. Kresse and D. Joubert, Phys. Rev. B: Condens. Matter Mater. Phys., 1999, 59, 1758-1775.

41 G. Makov and M. C. Payne, Phys. Rev. B: Condens. Matter Mater. Phys., 1995, 51, 4014-4022.

42 G. Mills, H. Jonsson and G. K. Schenter, Surf. Sci., 1995, 324, 305-337.

43 G. Henkelman, B. P. Uberuaga and H. Jónsson, J. Chem. Phys., 2000, 113, 9901-9904.

44 G. Henkelman and H. Jónsson, J. Chem. Phys., 1999, 111, 7010-7022.

45 A. Heyden, A. T. Bell and F. J. Keil, J. Chem. Phys., 2005, 123, 224101.

46 M. Garcia-Ratés and N. López, J. Chem. Theory Comput., 2016, 12, 1331-1341.

47 M. Garcia-Ratés, R. García-Muelas and N. López, J. Phys. Chem. C, 2017, 121, 13803-13809.

48 M. Álvarez-Moreno, C. de Graaf, N. López, F. Maseras, J. M. Poblet and C. Bo, J. Chem. Inf. Model., 2015, 55, 95103.

49 https://doi.org/10.19061/iochem-bd-1-44.

50 S. S. Sunu, E. Prabhu, V. Jayaraman, K. I. Gnanasekar, T. K. Seshagiri and T. Gnanasekaran, Sens. Actuators, B, 2004, 101, 161-174.

51 A. Borgschulte, O. Sambalova, R. Delmelle, S. Jenatsch, R. Hany and F. Nüesch, Sci. Rep., 2017, 7, 40761.

52 K. Inzani, M. Nematollahi, F. Vullum-Bruer, T. Grande, T. W. Reenaas and S. M. Selbach, Phys. Chem. Chem. Phys., 2017, 19, 9232-9245.

53 I. V. Kozhevnikov, Chem. Rev., 1998, 98, 171-198.

54 J. Macht, M. J. Janik, M. Neurock and E. Iglesia, J. Am. Chem. Soc., 2008, 130, 10369-10379.

55 I.-M. Mbomekallé, X. López, J. M. Poblet, F. Sécheresse, B. Keita and L. Nadjo, Inorg. Chem., 2010, 49, 70017006.

56 K. Maeda, H. Katano, T. Osakai, S. Himeno and A. Saito, J. Electroanal. Chem., 1995, 389, 167-173.

57 M. Sadakane and E. Steckhan, Chem. Rev., 1998, 98, 219238.

58 M. Capdevila-Cortada and N. López, ACS Catal., 2015, 5, 6473-6480.

59 M. Capdevila-Cortada, G. Vilé, D. Teschner, J. PérezRamírez and N. López, Appl. Catal., B, 2016, 197, 299-312.

60 P. Deshlahra and E. Iglesia, J. Phys. Chem. C, 2014, 118, 26115-26129.

61 P. Deshlahra, R. T. Carr, S.-H. Chai and E. Iglesia, ACS Catal., 2015, 5, 666-682.

62 Notice that $\mathrm{Mo}^{5+}$ centers are outliers in the fit for adsorption via electrostatic contributions. 